\title{
Development and application of a high sensitivity immunochromatographic test strip for detecting classical swine fever virus antibody
}

\author{
Yilin Bai ${ }^{1}$, Rui Jia ${ }^{2}$, Qiang $\mathrm{Wei}^{2}$, Li Wang ${ }^{2}$, Yaning Sun ${ }^{2}$, Yiwei $\mathrm{Li}^{3}$, Jun $\mathrm{Luo}^{2}$, and \\ Gaiping Zhang ${ }^{2}$ \\ ${ }^{1}$ Northwest Agriculture and Forestry University \\ ${ }^{2}$ Henan Academy of Agricultural Sciences \\ ${ }^{3}$ Henan Institute of Science and Technology
}

July 8, 2021

\begin{abstract}
Classical swine fever (CSF) is caused by classical swine fever virus (CSFV) and has led to huge ecnomic losses for the pig industry worldwide. Although vaccination and other control measures have been carried out, it is essential to establish a rapid and valid method for CSF vaccination monitoring and clinical diagnosis. CSFV E2 protein has been well-known as a major antigen for antibody detection. It is significant to improve affinity between E2 protein and CSFV antibody for a better performance of detection method. In this study, a recombinant E2 extracellular protein (aa 1-331), which has a native homodimer conformation and has a high affinity with anti-CSFV-E2 monoclonal antibody WH303, was expressed using Bacto-Bac baculovirus expression system. A novel immunochromatographic test strip based on the recombinant CSFV E2 protein was developed for CSFV antibody detection. The sensitivity of this strip for detecting CSFV standard positive serum was 1:102400, 4 times higher than that of the previously developed $\mathrm{CnC} 2$ test strip. No cross reaction with antibodies of other swine viruses was observed. The detection of clinical swine serum samples $(n=138)$ demonstrated that the agreements of this E2 test strip with three commercial ELISA kits were 88.40\% (122/138), 86.23\% (119/138), and 96.38\% (133/138), respectively. Our data indicated that a novel E2 test strip with higher sensitivity has been developed and can be applied for clinical sample detections, providing a new powerful and simple approach for CSFV antibody monitoring.
\end{abstract}

\section{Hosted file}

manuscript.doc available at https://authorea.com/users/424519/articles/529589-developmentand-application-of-a-high-sensitivity-immunochromatographic-test-strip-for-detectingclassical-swine-fever-virus-antibody 


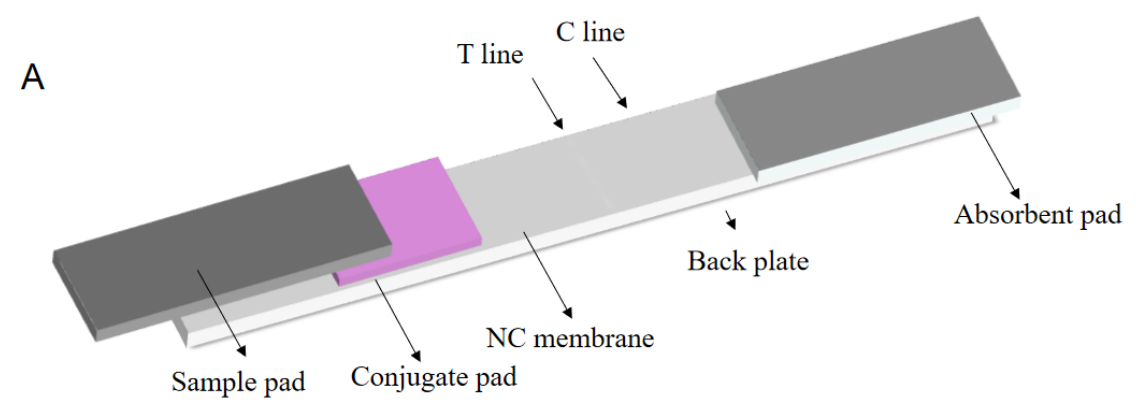

B

Packing in tinfoil gas with desicant and keeping far

Naked test paper tapes

Plastic casing type strips away from light and moisture
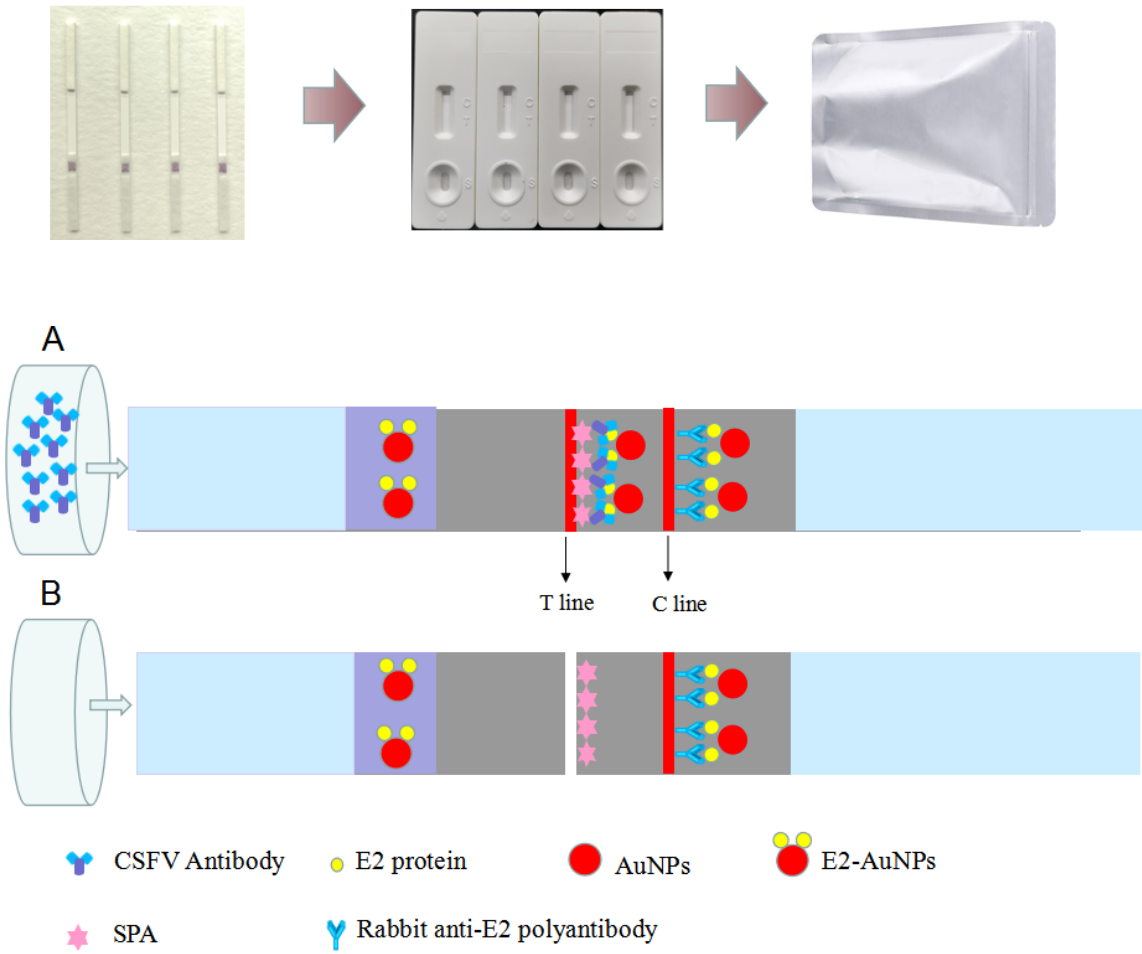

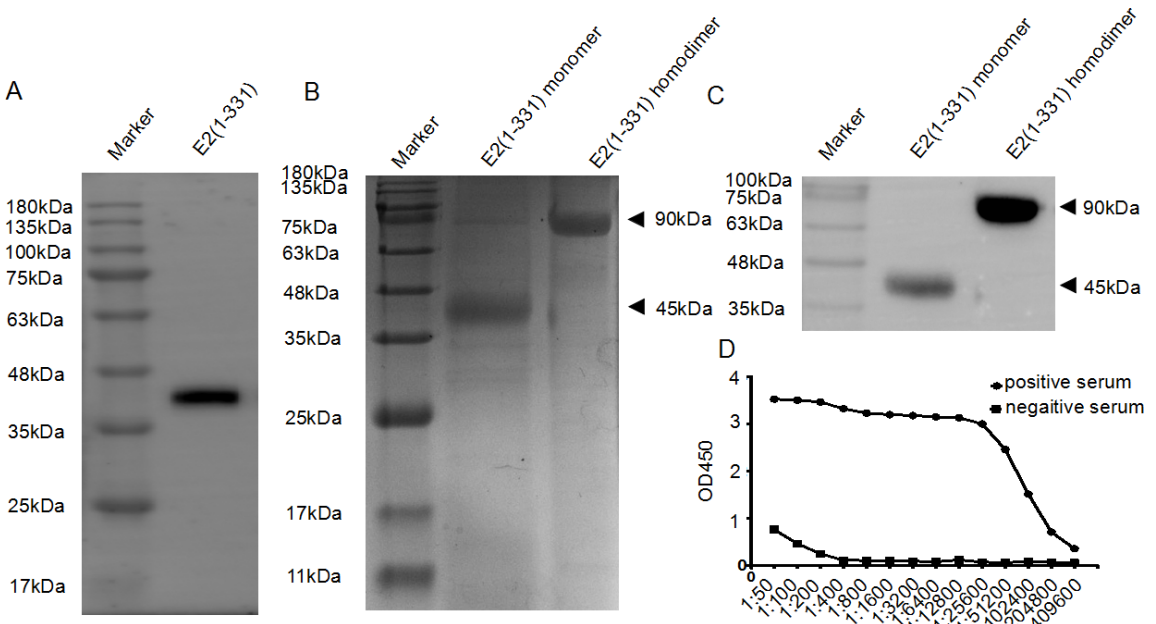

50000000000000000000

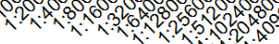

Concentration of E2 protein

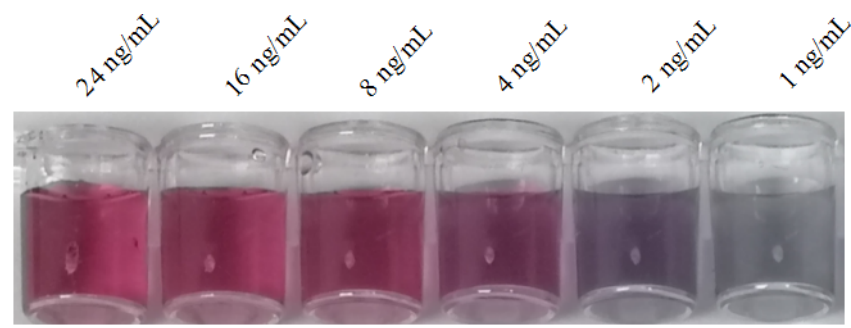

Solubleness

Dissolution

Sedimentation

Color change

Red

Gray purple 
A
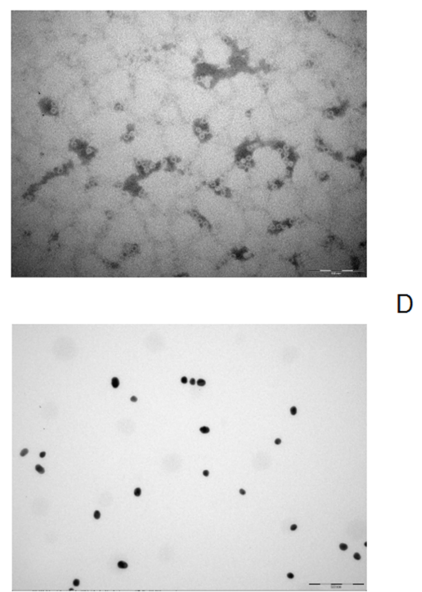

E

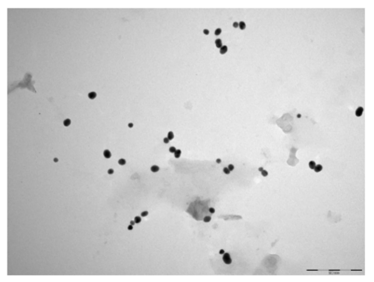

G

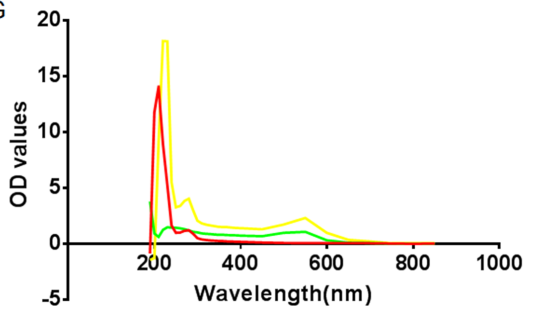

F

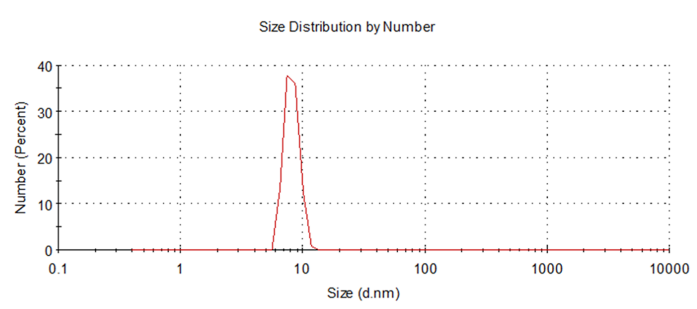

Size Distribution by Number
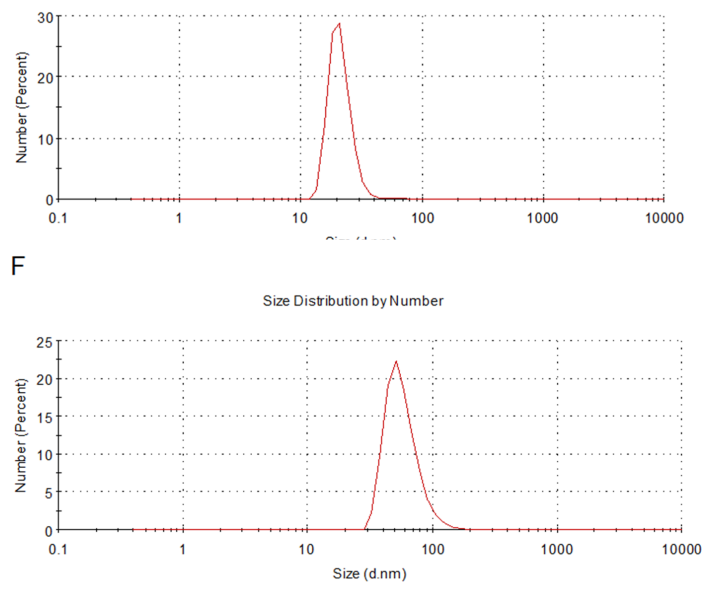

- E2

- AuNPs

E2-AuNPs 

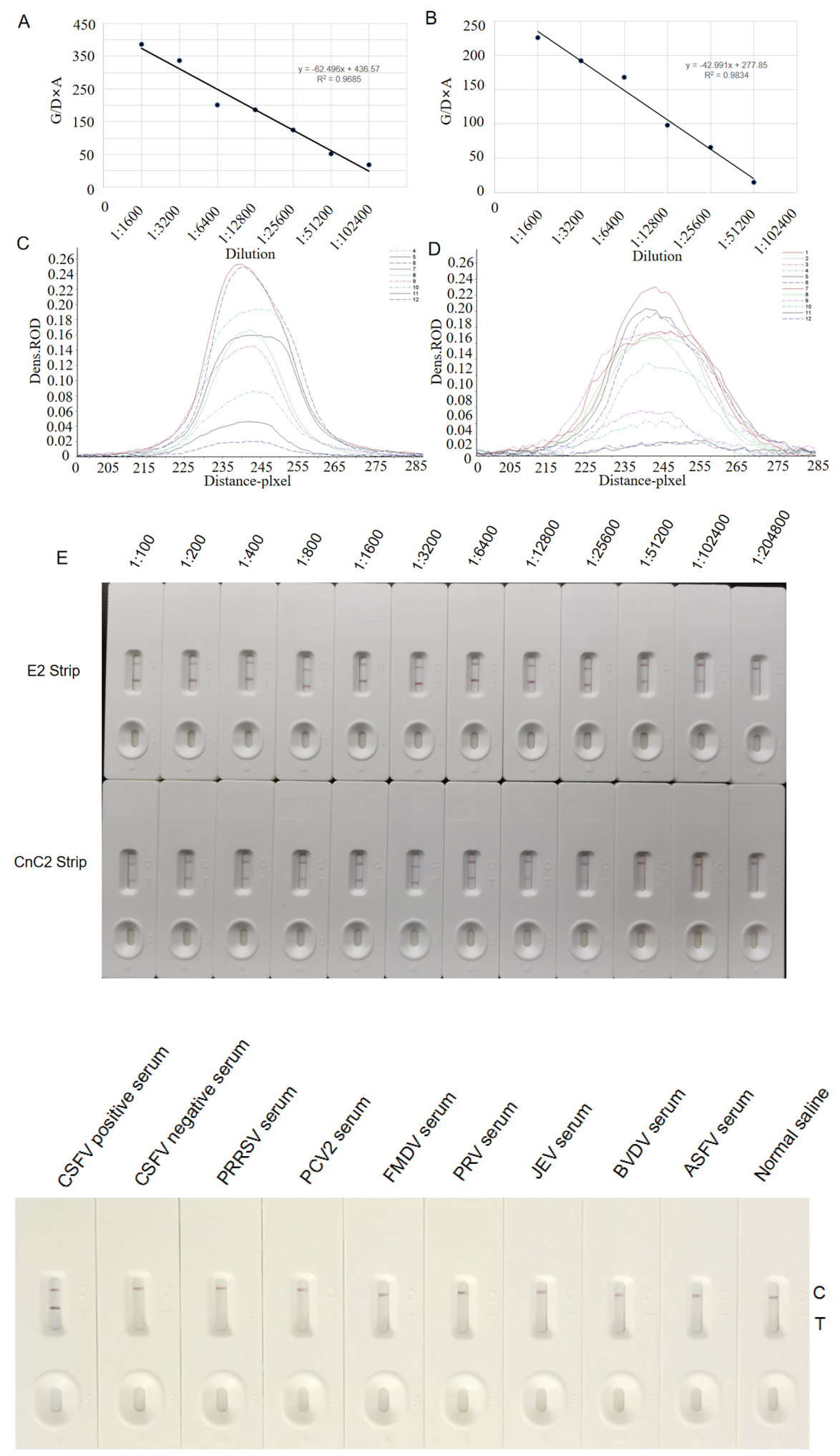